\title{
CORRIGENDUM
}

\section{Long-term effects of a high-protein, low-carbohydrate diet on weight control and cardiovascular risk markers in obese hyperinsulinemic subjects}

GD Brinkworth, M Noakes, JB Keogh, ND Luscombe, GA Wittert and PM Clifton

International Journal of Obesity (2004) 28, 1187. doi:10.1038/sj.ijo.0802766

Correction to: International Journal of Obesity (2004) 28, 661-670. doi: 10.1038/sj.ijo.0802617

Since the publication of the above paper, the authors have identified an error in the abstract, where an incorrect $P$-value was given. The corrected sentence is given here:
At week 68, there was net weight loss (SP $-2.9 \pm 3.6 \%$, HP $-4.1 \pm 5.8 \% ; P<0.44)$ due entirely to fat loss $(P<0.001)$ with no diet effect. 